\title{
Quantification by FT-IR (UATR/NIRA) of NBR/SBR blends
}

\author{
Joyce Baracho Azevedo ${ }^{1,2}$, Lidia Mattos Silva Murakami ${ }^{1,2}$, Ana Carolina Ferreira ${ }^{3}$, Milton Faria Diniz \\ Leandro Mattos Silva ${ }^{5}$ and Rita de Cássia Lazzarini Dutra ${ }^{1^{*}}$
}

\author{
${ }^{1}$ Instituto Tecnológico de Aeronáutica - ITA, São José dos Campos, SP, Brasil \\ ${ }^{2}$ Tenneco Automotive Brasil, Cotia, SP, Brasil \\ ${ }^{3}$ General Motors do Brasil - GM, São Caetano do Sul, SP, Brasil
}

${ }^{4}$ Divisão de Química - AQI, Instituto de Aeronáutica e Espaço - IAE, São José dos Campos, SP, Brasil

${ }^{5}$ Petroquímica Braskem S.A., Santo André, SP, Brasil

*ritacld@ita.br

\begin{abstract}
Rubber blends are important materials in automotive industry, as well as in other sectors. However, there are implications when suitable use of a polymer in an artifact is not made. In the automotive area, for example, the use of an elastomer without the fuel resistance requirement would result in component degradation, potential fuel leakage, and danger of fire. The use of polymer blends may be the solution to this problem. Fourier transform infrared spectroscopy (FT-IR) can be used for the knowledge of the polymer content of these blends. Then, FT-IR quantitative methodologies for determining acrylonitrile-butadiene copolymer (NBR) copolymer and butadiene-styrene copolymer (SBR) contents were developed by the transflectance accessory, NIRA, and the transmission mode, being the sample analyzed by transmission and universal attenuated total reflection (UATR) in the medium infrared (MIR). UATR and NIRA methodologies showed better accuracy. However, the MIR analysis showed a detection limit between $10-20 \%$ of NBR.
\end{abstract}

Keywords: content, NBR, NIRA, SBR, UATR.

\section{Introduction}

In contrast to the deceleration in the new polymers production, there is a growing interest in the processes research and development for the modification of existing polymers ${ }^{[1]}$. In this context, polymer blends are available for specific applications. According to the literature, the necessary condition is that the lower content of one of components must exceed at least $5 \% 0^{[2,3]}$.

Blends are often used to improve properties of each polymer involved in the product, process and/or reduce cost. There are many applications in several industries, such as aeronautics, naval, automotive, graphics, real estate, among others. Therefore, studies involving polymers and their blends are attractive, since the methodologies developed can be used in different sectors ${ }^{[1,4]}$.

Butadiene-based copolymers are widely used in automotive industry. Among these, the SBR and NBR copolymers are outstanding. SBR plays a major role in the market due to its application in tires production. When SBR is used in conjunction with the BR-high cis butadiene homopolymer, excellent properties are obtained for application to tire tread. Since year 2000, automobile and tire manufacturers have been concerned about the environment and which led them to invest in new cleaner synthetic processes for production of these elastomers. Butadiene is a monomer used in the manufacture of elastomers of great economic interest worldwide. According to their properties, the polymers are assigned to a specific type of use $\mathrm{e}^{[5]}$.
There are several blends available in the world market, but for the purpose of this paper, the blend composed of NBR and SBR copolymers was selected based on its properties which are suitable on lowering costs by improving certain properties of NBR rubber, which has good chemical and oil resistance. However, these properties vary according to a considerable number of rubber products. Higher the acrylonitrile (AN) content, greater the oil resistance, however lower the flexibility. It is possible to use a NBR blend of high content AN with SBR rubber to obtain an oil resistance degree as such a NBR with low content of AN, with an overall economy in cost. NBR products with high AN content tends to shrink in contact with lubricating oils, in high temperature. The manufacture of NBR/SBR blends constitutes a solution for the final artifact achieve desired properties. SBR can also improve NBR processing ${ }^{[6]}$.

In the automotive industry, NBR is usually applied in hoses that have direct contact with fuels or gases ${ }^{[5]}$. NBR is also used in the aerospace industry, as rocket motor thermal insulation $^{[7]}$. It comes to our attention that the quality of the product delivered by the supplier might not meet the specification needed, consisting only by NBR. This may lead to detachments compromising the integrity of the rubber / propellant interface.

NBR rubber also benefits aeronautics industry on appliances as such hoses, seals, and self-sealing fuel and oil tanks. It is applied in the nuclear industry to make protective gloves. NBR property of withstanding a temperature range 
of -40 to $108^{\circ} \mathrm{C}$ makes it the ideal material for aeronautical applications. Still, NBR can be applied to create molded products, adhesives, sealants, sponges, expanded foams and carpets $^{[8]}$.

A variation in polymerization, $\mathrm{AN}$ ratio to butadiene, processing properties and vulcanization are characteristics added in NBR / SBR blend by NBR rubber worth to mention. The AN content is one of the main criteria to define the basic properties of an elastomer. Nitrile group polarity grants to elastomers resistance to oils and hydrocarbon-based solvents, flexibility and abrasion resistance ${ }^{[5]}$. In this paper, a NBR rubber with AN content of $37-41 \%$ was used according to NBR supplier. Additionally, a FT-IR methodology developed by the group ${ }^{[9]}$ was applied to precisely acquire the $\mathrm{AN}$ value.

The AN content determination in NBR have been performed by FT-IR transmission with values reference obtained by Kjeldhal method ${ }^{[10]}$, measuring contents up to around $40 \%$. FT-IR transmission and reflection (UATR) techniques ${ }^{[9]}$ were used for determining contents up to around $50 \%$, with good results, indicating that UATR methodology presents better linear correlation and less analysis time.

One of the most common blend elastomer is the SBR responsible for nearly $40 \%$ of all synthetic rubber used in the world. According to data from 2007, approximately 2.4 million tons of SBR per year were already produced in the world ${ }^{[5]}$. SBR rubber characteristics depend on styrene content, which can vary between 10 and $85 \%$. Formulations with low styrene content exhibit an elastomeric behavior, whereas those with high styrene content have a thermoplastic nature ${ }^{[11]}$. SBR-1502 was object of this study, with $23.5 \%$ styrene, obtained by cold polymerization $\left(10^{\circ} \mathrm{C}\right.$ maximum $)$ in emulsion of fatty and resinous soaps, coagulated in a salt / acid or acid system and stabilized with a non-smelly antioxidant.

SBR rubber has good mechanical properties, high resistance. Likewise, it has good resistance to abrasion, ozone and weathering, but regarding to oil resistance it presents a gap, making this mixture with NBR beneficial for both copolymers, dependent on the suitable application of the final artifact ${ }^{[12]}$.

The property variations are dependent on the functional groups content of the polymers and also compounds present in the product composition. Therefore, the possibility of using blends to reach a specific application indicates the need for suitable characterization and/or quantification of these materials. Instrumental techniques, mainly Fourier transform infrared spectroscopy (FT-IR), associated or not with other techniques, is mentioned in the literature for this goal, including also studies of polymers used in the automotive and aerospace industry, such as NBR, SBR and their polymer blends ${ }^{[13-18]}$.

Table 1 shows some studies. Although good results were achieved in these studies, some observations were made in this study, which served as a basis for the elaboration of the methodology currently developed.

It is observed that the MIR region is the most used, just as the technique obtaining FT-IR spectra is the conventional one, which means transmission and the use of other instrumental

Table 1. Main aspects cited by studies on polymers and their blends characterization.

\begin{tabular}{|c|c|c|c|}
\hline Author & Year & Main conclusion & Coments \\
\hline \multirow[t]{2}{*}{ Shield et al. ${ }^{[19]}$} & 2003 & $\begin{array}{l}\text { FT-MIR Analysis (medium infrared) and FT-NIR (near } \\
\text { infrared) were used to NBR/SBR determination. Obtaining } \\
\text { modes: MIR - transmission and ATR/ NIR - optical } \\
\text { fiber - NBR band }-2240 \mathrm{~cm}^{-1} \text { and SBR }-1600 \mathrm{~cm}^{-1} \text {. } \\
\text { NIR range }-5443-6103 \mathrm{~cm}^{-1} \text {. }\end{array}$ & $\begin{array}{l}\text { Although the relative error of methodology was compared } \\
\text { with methods as TGA }(10 \%) \text {, a medium intensity band } \\
\left(1600 \mathrm{~cm}^{-1}\right) \text { was used for SBR, which may probably cause } \\
\text { a greater error than if it were used at } 700 \mathrm{~cm}^{-1} \text {, for lower } \\
\text { contents of this polymer. }\end{array}$ \\
\hline & & Methodology errors MIR $-4 \%$ and NIR $-2 \%$. & \\
\hline Dutra et al. ${ }^{[17]}$ & 2004 & $\begin{array}{l}\text { NR/SBR blends were analyzed by FT-IR transmission/ } \\
\text { controlled pyrolysis and TGA/DTG, with linear correlation } \\
0.998 \text { and methodology error } 1.73 \% \text {, within the accuracy } \\
\text { limits of the equipment. }\end{array}$ & $\begin{array}{l}\text { Controlled pyrolysis technique, while accurate, involves } \\
\text { elaborate sample preparation and requires reasonable } \\
\text { analysis time. Using thermal analysis technique to } \\
\text { validate data, although more accurate, is more complex, } \\
\text { depending on the rubbers degradation temperatures being } \\
\text { adequate, that is the degradation of one rubber finish } \\
\text { before the other begins. }\end{array}$ \\
\hline Berridi et al. ${ }^{[20]}$ & 2006 & $\begin{array}{l}\text { NR/SBR blends were analyzed by FT-IR transmission / } \\
\text { pyrolysis in Bunsen burner and TGA/DTG. FT-IR was } \\
\text { more effective in the determination. }\end{array}$ & $\begin{array}{l}\text { Pyrolysis technique in Bunsen burner is less precise than } \\
\text { the controlled one, however, relative bands were used. } \\
\text { There was no comment on methodology errors. }\end{array}$ \\
\hline $\begin{array}{l}\text { Chakraborty et al. } \\
{[11]}\end{array}$ & 2007 & $\begin{array}{l}\text { Determination of acrylonitrile (AN) content in NBR } \\
\text { gum (without additives) by FT-IR transmission/cast film, } \\
\text { with reference values obtained by the Kjeldhal method, } \\
\text { measuring contents up to around } 40 \% \text {. }\end{array}$ & $\begin{array}{l}\text { Cast film technique involves solvent use, elaborated } \\
\text { sample preparation, and there may be interference } \\
\text { associated with the solvent/polymer interaction, and } \\
\text { requires reasonable analysis time. Validation by Kjeldhal } \\
\text { or any other instrumental method, although more precise, } \\
\text { implies knowledge of both techniques for elaboration of } \\
\text { the calibration curve. }\end{array}$ \\
\hline Lee et al. ${ }^{[21]}$ & 2007 & $\begin{array}{l}\text { NR, SBR and BR content determination in a ternary mixture } \\
\text { of these elastomers by transmission/pyrolysis FT-IR in } \\
\text { Bunsen burner, TGA, DSC and by gas chromatography and } \\
\text { mass spectrometry coupling by pyrolysis (Py-GC / MS). } \\
\text { This last method was more precise, there was interference } \\
\text { of one elastomer in the other, with the other techniques. }\end{array}$ & $\begin{array}{l}\text { There was considerable variation in contents determination, } \\
\text { especially by TGA and FT-IR, but it should also be } \\
\text { considered that the use of coupling techniques requires } \\
\text { specialists in both areas, in this case, chromatography } \\
\text { and mass, for better results interpretation. }\end{array}$ \\
\hline
\end{tabular}


Table 1. Continued...

\begin{tabular}{|c|c|c|c|}
\hline Author & Year & Main conclusion & Coments \\
\hline Sanches et al. ${ }^{[9]}$ & 2008 & $\begin{array}{l}\text { Determination of acrylonitrile (AN) content in NBR } \\
\text { non-vulcanized/vulcanized by FT-IR transmission / } \\
\text { pyrolysis in Bunsen burner and controlled, with solvent } \\
\text { extraction and by UATR, as received, measuring contents } \\
\text { up to around } 50 \% \text {. Techniques presented similar precision, } \\
\text { but UATR was more adequate to the determination, due } \\
\text { to the shorter analysis time and the smaller amount of } \\
\text { sample used. }\end{array}$ & $\begin{array}{l}\text { UATR method was used to determine the AN content in } \\
\text { the rubber used in this study. }\end{array}$ \\
\hline Harada $^{[22]}$ & 2016 & $\begin{array}{l}\text { It focuses on rubber analysis techniques, such as infrared, } \\
\text { TGA, Py-GC/MS, but in the FT-IR analysis the focus is on } \\
\text { qualitative reflection analysis for component verification. }\end{array}$ & $\begin{array}{l}\text { The quantitative part is also centered on the Py-GC/MS } \\
\text { analysis. FT-IR is cited qualitatively. }\end{array}$ \\
\hline Ujianto et al. ${ }^{[23]}$ & 2017 & It focuses on FT-IR of NR & $\begin{array}{l}\text { Qualitative analysis, aiming at the evaluation of spectrometric } \\
\text { changes, resulting from devulcanization. }\end{array}$ \\
\hline Datta et al. ${ }^{[24]}$ & 2017 & $\begin{array}{l}\text { Determination of NR, SBR and BR contents in ternary } \\
\text { mixture by FT-IR and TGA. Bands } 1375(\mathrm{NR}), 699 \text { (SBR) } \\
\text { and } 738(\mathrm{BR}) \mathrm{cm}^{-1} \text { and relative bands were used in the } \\
\text { FT-IR methodology. }\end{array}$ & $\begin{array}{l}\text { The vinylidene band at } 885 \mathrm{~cm}^{-1} \text {, which would be more } \\
\text { characteristic of NR, could have been tested. }\end{array}$ \\
\hline
\end{tabular}

techniques. However, it validates the FT-IR data and makes the methodology more complex and time-consuming. Methodological errors are not generally compared. In this paper, it was proposed a FT-IR methodology in the MIR region, with data validation in the NIR region, by means of less conventional spectral modes, such as UATR and NIRA, compared to data obtained by transmission. The samples were prepared by pyrolysis in a Bunsen burner, with evaluation of FT-IR methodology error.

\section{Materials and Methods}

\subsection{Samples}

Nine samples of NBR/SBR blends were prepared at Tenneco Automotive Brazil, with materials kindly provided by the company, in the proportions $10 / 90,20 / 80,30 / 70$, $40 / 60,50 / 50,60 / 40,70 / 30,80 / 20,90 / 10$, according to the formulation found in Table 2.

\subsubsection{Preparation of rubber samples}

The raw material was weighed on a precision scale and all components, except sulfur and accelerators, tetramethylthiuram disulfide (TMTD), (1,3-Dimethylbutyl)N'-phenyl-phenylenediamine (6PPD), N-(cyclohexylthio) phthalimide (PVI) and 4,4 Dithiomorpholine (DTDM), which were mixed in banbury of 2 liters per 240 seconds, with a pound pressure of $4 \mathrm{kgf} / \mathrm{cm}^{2}$, rotation of $70 \mathrm{rpm}$ and initial temperature of $40^{\circ} \mathrm{C}$, for production of master batch. It was processed into a roller form six times in a lab open mill with a rotation of $40 \mathrm{rpm}$. Later, the master batch was accelerated at banbury, with the rest of the weighted components (TMTD, 6PPD, PVI, DTDM and sulfur) for 120 seconds, with $4 \mathrm{kgf} / \mathrm{cm}^{2}$ pound pressure, $70 \mathrm{rpm}$ rotation and initial temperature of $40^{\circ} \mathrm{C}$. Then the rubber was homogenized in roller form six times in an open mil lab with a rotation of $40 \mathrm{rpm}$ and withdrawn into blanked. For the preparation of vulcanized rubber sheet, a hydraulic press with vulcanization time of $6 \mathrm{~min}$, plateaus temperature of $160^{\circ} \mathrm{C}$ and $150 \mathrm{kgf} / \mathrm{cm}^{2}$ of closing pressure was used.

\subsection{Equipment of characterization/conditions}

\subsubsection{FT-IR analysis}

The samples were analyzed in Spectrum One PERKINELMER FT-IR spectrometer (MIR regions of 4000 to $400 \mathrm{~cm}^{-1}$ and NIR of 12000 to $4000 \mathrm{~cm}^{-1}$, $4 \mathrm{~cm}^{-1}$ resolutions, gain 1,20 scans), being spectra obtained by transmission techniques (MIR and NIR) and reflection (MIR), using the UATR accessory, and in NIR region, also using the Frontier PERKINELMER FT-IR spectrometer, NIRA accessory, being all samples of different methodologies, prepared by pyrolysis in Bunsen burner.

In Bunsen's pyrolysis, samples of each rubber blend were cut, extracted for 8 hours in a Soxhlet extractor, using methanol as solvent ${ }^{[25]}$. After solvent evaporation in the oven, it was put a quantity of about $0.5 \mathrm{~g}$ of sample in each pyrolysis tube. The tubes were flamed in Bunsen burner, at the same flame height (marked with the aid of an universal device and a claw to determine the same pyrolysis position). For the transmission analysis, by pyrolysis, was used the $0.025 \mathrm{~mm}$ spacer.

By reflection, using the UATR accessory, in the same way that was done in a recent study by Rigoli et al. ${ }^{[26]}$, the pyrolysis samples were analyzed by placing them in contact with the diamond-coated zinc selenide crystal surface with $120 \mathrm{~N}$ (Newton) torque application.

For MIR analysis, the nine NBR/SBR samples (composition already shown in Table 2), prepared by pyrolysis in Bunsen burner and analyzed by transmission and reflection (UATR), were used to prepare $\mathrm{A}_{\mathrm{NBR}} / \mathrm{A}_{\mathrm{SBR}} \mathrm{x}[\mathrm{NBR}] /[\mathrm{SBR}]$ analytical curve, aiming the NBR and SBR contents determination, through the relative band $\mathrm{A}_{2237} / \mathrm{A}_{700}$. This band is composed by analytical absorptions of stretching (v) $\mathrm{C} \equiv \mathrm{N}$ of NBR $\left(2237 \mathrm{~cm}^{-1}\right)$ and bending

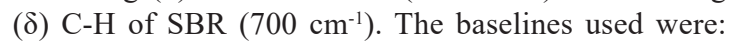
2275-2150 $\mathrm{cm}^{-1}$ (band $2237 \mathrm{~cm}^{-1}$ ) and 2150-590 $\mathrm{cm}^{-1}$ (band $700 \mathrm{~cm}^{-1}$ ), for transmission / pyrolysis methodology, and $2275-2180 \mathrm{~cm}^{-1}$ (band $2237 \mathrm{~cm}^{-1}$ ), 858-642 $\mathrm{cm}^{-1}$ (band $700 \mathrm{~cm}^{-1}$ ) for UATR methodology. 
Table 2. NBR/SBR Blend Formulation System.

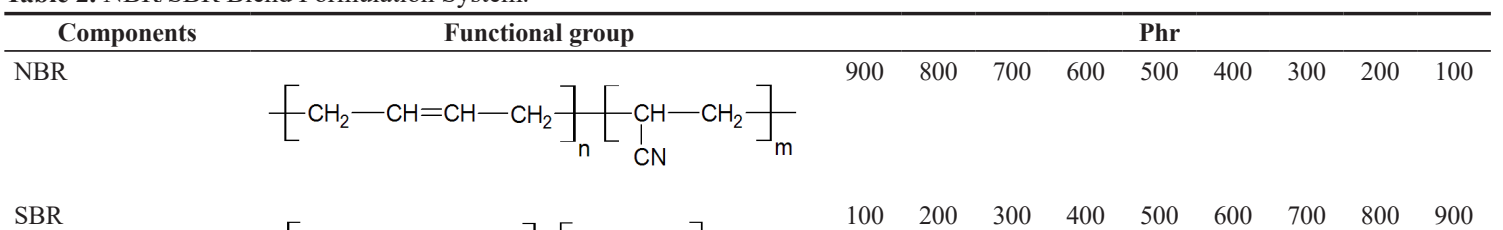<smiles>C#CC1CCC2C3CCC(C(C)C)CCC1C2C(=O)C3C</smiles>

Zinc Oxide

$\mathrm{ZnO}$

Stearic Acid<smiles>CCCCCCCCCCCCCCCCCC(=O)O</smiles>

DTDM

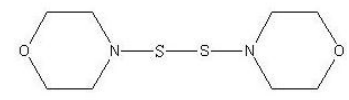

For the NIR methodology, the same number of reference NBR / SBR samples, prepared by pyrolysis in Bunsen burner and analyzed by transmission, were used to prepare the analytical curve $\mathrm{A}_{4336} / \mathrm{A}_{4060} \mathrm{x}[\mathrm{NBR}] /[\mathrm{SBR}]$. The bands chosen are in the region of combination or overtones of fundamental bands. In the case of NBR/SBR blend, the band $\mathrm{A}_{4336}$ is probably attributed to the first overtone of stretching (v) of $\mathrm{C} \equiv \mathrm{N}$ group of NBR or of combination bands, and the $\mathrm{A}_{4060}$ to the second overtone of bending $(\delta)$ of SBR aromatic $\mathrm{CH}$ groups ${ }^{[19,27]}$. The baseline used was $4540-4000 \mathrm{~cm}^{-1}$ (bands 4336 and $4060 \mathrm{~cm}^{-1}$ ). For NIRA methodology, the same number of samples and the same analytical bands were used. The samples were also prepared by pyrolysis in Bunsen burner, and were analyzed by transflectance because they were in the liquid state ${ }^{[28]}$. The baseline used was 4780 to $4000 \mathrm{~cm}^{-1}$.

The data of all FT-IR/MIR and NIR methodologies, for each sample, represent the median of 5 values of analytical bands intensity chosen, being that the mean standard deviations (Equations 1 and 2) and the relative error (RD)
(Equation 3) were calculated by non-parametric treatment in agreement with Hórak ${ }^{[29]}$ and with the methodology adopted successfully in group quantitative studies for rubber and other materials ${ }^{[17,28,30]}$.

$$
\begin{aligned}
& \hat{\sigma}_{\hat{\mu}}=\frac{\hat{\sigma}}{\sqrt{n}} \\
& \hat{\sigma}=K_{R} \times R
\end{aligned}
$$

Where, $\hat{\sigma}$ is the mean standard deviation, $n$, the measurements number, $\mathrm{R}$ is the difference between the highest and the lowest values of absorbance. $\mathrm{K}_{\mathrm{R}}$ is the coefficient to calculate the standard deviation $(\hat{\sigma})$ of a range of values, with $\mathrm{K}_{\mathrm{R}}=0.430$ for 5 experiments ${ }^{[29]}$. The RD of the measurements for each analyzed sample, given in \%, was determined by Equation 3, where $\mu$ is the median value of A. The median of the relative errors represents the error of the methodology $\mathrm{y}^{[17,28,30]}$.

$$
R D_{(\%)}=\frac{\hat{\sigma}_{\hat{\mu}}}{\mu} \times 100
$$




\section{Results and Discussion}

\subsection{FT-IR analysis}

In this topic the following were addressed: a) the determination by UATR of AN content of NBR used in the blends, according to methodology previously developed by the group ${ }^{[9]}$, since only one range was furnished by the supplier. For SBR rubber, the determined value as reported by the supplier was used. These values were not used in the blends contents calculation, only used for the proper characterization of the raw materials used for the prediction of properties of blends, for future and specific applications. b) the determination of the NBR/SBR blends in two spectral regions, by different ways of obtaining spectra, aiming to evaluate the most suitable conditions for this type of analysis.

\subsection{Determination by UATR of AN content of NBR used in the blend}

In Table 3, the data for AN content in NBR calculation are inserted.

\subsection{MIR/transmission analysis of NBR/SBR}

In Figure 1, are the MIR/transmission spectra of some NBR/SBR blends studied. It can be observed that the bands intensities $\mathrm{A}_{2237}$ and $\mathrm{A}_{700}$ increase and decrease according to the content of NBR and SBR, respectively, as expected by Lambert-Beer Law, for quantitative analyzes ${ }^{[32]}$. The data for elaboration of calibration curve are shown in Table 4 and Figure 2. To overcome liquid film thickness issues and to improve the data accuracy ${ }^{[32]}$, mean values of relative band $\mathrm{A}_{2237} / \mathrm{A}_{700}$ were considered as a function of the relative NBR/SBR concentration.

From the calibration curve (Table 4), the following correlation (Equation $4-\mathrm{R}=0.98$, with $96 \%$ of the values explained by the methodology, $\mathrm{R}^{2}=0.96$ ) is proposed:

$$
A_{2237} / A_{700}=0.17[N B R] /[S B R]+0.14
$$

To find the two elastomers contents of the unknown mixture, Equation 5 should also be used. This is valid for all the methodologies developed in this study.

Table 3. UATR data for determination of AN in NBR.

\begin{tabular}{|c|c|c|c|c|c|c|}
\hline Sample & $\mathbf{A}_{2237}$ & $\begin{array}{c}\mathbf{A}_{2237} \\
\text { (MEDIAN) }\end{array}$ & $\begin{array}{c}\text { Mean standard } \\
\text { deviation }\end{array}$ & $\operatorname{RD}(\%)$ & $\begin{array}{c}\text { Calculated } \\
\text { acrylonitrile } \\
\text { content }^{[9]} \\
(\%)(*)\end{array}$ & $\begin{array}{c}\text { Acrylonitrile } \\
\text { content }(\%) \\
\text { range, reported } \\
\text { by NBR gum } \\
\text { supplier }(* *)\end{array}$ \\
\hline \multirow[t]{5}{*}{ NBR } & 0.040 & 0.040 & 0.001 & 2.5 & $30 \pm 1$ & $37-41$ \\
\hline & 0.039 & & & & & \\
\hline & 0.040 & & & & & \\
\hline & 0.040 & & & & & \\
\hline & 0.040 & & & & & \\
\hline
\end{tabular}

(*) $\mathrm{y}=0.0014 \mathrm{x}-0.002-$ calibration curve, where $\mathrm{y}=$ median value of $\mathrm{A}_{2237}{ }^{[9]}$;

(**) Only the range of AN content was reported by NBR (gum) supplier, without the determined value, nor what method was used. Therefore, the value considered for the material characterization was obtained, that is, $30 \pm 1 \%$, of medium AN content ${ }^{[31]}$ by the FT-IR methodology, previously developed ${ }^{[9]}$, which is accurate, that is, with the relative error around $2 \%$, under the conditions used (UATR, sample analyzed as received). It is interesting to note that the content found is also used for applications aerospace ${ }^{[9]}$, around $33 \%$.

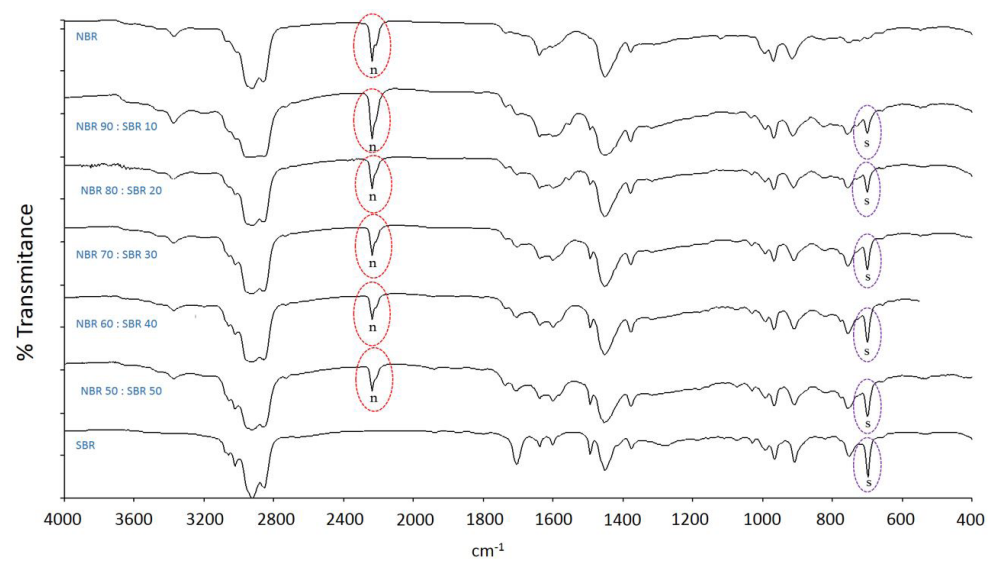

Figure 1. MIR/transmission spectra (Bunsen burner pyrolysis) of NBR/SBR blends, with AN and styrene bands, marked with $\mathrm{n}$ and $\mathrm{s}$, respectively. 
Table 4. MIR/transmission data (Bunsen burner pyrolysis) for calibration curve elaboration and associated methodology errors.

\begin{tabular}{|c|c|c|c|}
\hline $\begin{array}{c}\mathrm{NBR} / \mathrm{SBR} \\
\text { (Relative Concentration) }\end{array}$ & $\begin{array}{c}\mathbf{A}_{2237} / \mathbf{A}_{700} \\
\text { Median }\end{array}$ & Mean standard deviation & RD \% \\
\hline $\begin{array}{c}90 / 10 \\
(9.0)\end{array}$ & 1.563 & 0.013 & 0.83 \\
\hline $\begin{array}{c}80 / 20 \\
(4.0)\end{array}$ & 0.984 & 0.007 & 0.71 \\
\hline $\begin{array}{c}70 / 30 \\
(2.3)\end{array}$ & 0.608 & 0.004 & 0.66 \\
\hline $\begin{array}{c}60 / 40 \\
(1.5)\end{array}$ & 0.394 & 0.011 & 2.79 \\
\hline $\begin{array}{c}50 / 50 \\
(1.0)\end{array}$ & 0.401 & 0.024 & 5.99 \\
\hline $\begin{array}{l}40 / 60 \\
(0.67)\end{array}$ & 0.239 & 0.010 & 4.18 \\
\hline $\begin{array}{l}30 / 70 \\
(0.43)\end{array}$ & 0.142 & 0.007 & 4.93 \\
\hline $\begin{array}{l}20 / 80 \\
(0.25)\end{array}$ & 0.108 & 0.007 & 6.48 \\
\hline $\begin{array}{l}10 / 90 \\
(0.11)\end{array}$ & 0.067 & 0.010 & 14.93 \\
\hline
\end{tabular}

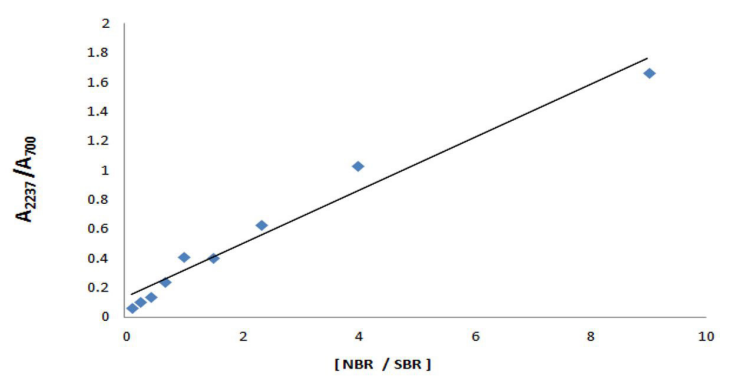

Figure 2. MIR/transmission calibration curve $\mathrm{A}_{2237} / \mathrm{A}_{700}$ versus relative concentration $[\mathrm{NBR} / \mathrm{SBR}]$.

$$
[N B R]+[S B R]=100 \%
$$

The methodology error, which is relative errors median ${ }^{[28]}$ calculated in Table 4, already mentioned, $4.18 \%$, can be considered good, compared to the reference value $^{[29]}, \leq 2 \%$, which is usually only found under fixed conditions, ideal for sample preparation, that is, in solution form and analyzed in closed cell, with thickness control. The error falls to $2.79 \%$, closer to the accuracy limit of the equipment, $\leq 2 \%$, for optimal condition, if the contents of $10-20 \%$ of NBR are not considered, may suggest a limit of detection in this range, by this methodology, probably due to the low intensity of the AN band, for these levels.

\subsection{MIR/UATR analysis of NBR/SBR}

In Figure 3, the MIR/UATR spectra of some studied NBR/SBR polymer blends are included. As for transmission MIR spectra, it can be observed that the intensities of bands $\mathrm{A}_{2237}$ and $\mathrm{A}_{700}$ increase and decrease according to the NBR and SBR content, respectively, as expected by the Lambert-Beer Law. The data for calibration curve elaboration are shown in Table 5 and Figure 4. In this methodology, $\mathrm{A}_{2237} / \mathrm{A}_{700}$ relative band was also used to improve the accuracy of the data.

From the calibration curve (Table 5), the following correlation (Equation $6-\mathrm{R}=0.98$, with $96 \%$ of the values explained by the methodology, $\mathrm{R}^{2}=0.96$ ) is proposed:

$$
A_{2237} / A_{700}=0.05[N B R] /[S B R]+0.03
$$

The methodology error, which is the median of the relative errors (Table 5), 3.41\%, can be considered good compared to the reference value, $\leq 2 \%$. The error falls to $2.09 \%$, closer to the accuracy limit of the equipment, $\leq 2 \%$, for optimal condition, if the contents of $10-20 \%$ of NBR are not considered, and may also suggest a limit of detection in this band, by this methodology, probably due to the low intensity of the AN band, for these levels.

\subsection{NIR/transmission analysis of NBR/SBR}

In Figure 5, the NIR/transmission (pyrolysis in Bunsen burner) spectra of some NBR / SBR polymer blends studied are shown. As for MIR and UATR spectra, it can be observed that the intensities of the bands $\mathrm{A}_{4336}$ and $\mathrm{A}_{4060}$ increase and decrease according to the NBR and SBR content, respectively, as expected by the Lambert-Beer Law.

In this methodology, the relative band $\mathrm{A}_{4336} / \mathrm{A}_{4060}$ was chosen to overcome liquid film thickness issues and to improve the data accuracy. Table 6 shows the values used, as well as their mean and relative deviations. 
Table 5. MIR/UATR data (Bunsen burner pyrolysis) for calibration curve elaboration and associated methodology errors.

\begin{tabular}{cccc}
\hline $\begin{array}{c}\text { NBR/SBR - (Relative } \\
\text { Concentration) }\end{array}$ & $\mathbf{A}_{2237} / \mathbf{A}_{700 \text { (Median) }}$ & Mean standard deviation & RD (\%) \\
\hline $90 / 10(9.0)$ & 0.431 & 0.009 & 2.09 \\
$80 / 20(4.0)$ & 0.263 & 0.005 & 1.90 \\
$70 / 30(2.3)$ & 0.187 & 0.003 & 1.60 \\
$60 / 40(1.5)$ & 0.111 & 0.002 & 3.41 \\
$50 / 50(1.0)$ & 0.088 & 0.003 & 6.38 \\
$40 / 60(0.67)$ & 0.047 & 0.003 & 6.67 \\
$30 / 70(0.43)$ & 0.030 & 0.002 & 7.14 \\
$20 / 80(0.25)$ & 0.014 & 0.001 & 30.00 \\
\hline
\end{tabular}

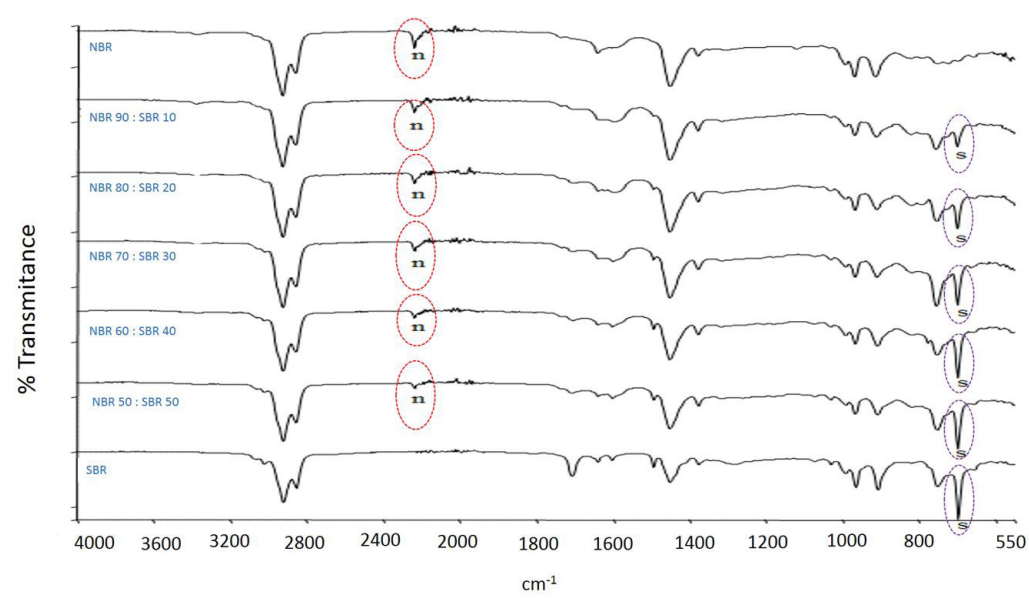

Figure 3. MIR/UATR spectra of NBR/SBR blends, with the AN and styrene bands, labeled with $\mathrm{n}$ and s, respectively.

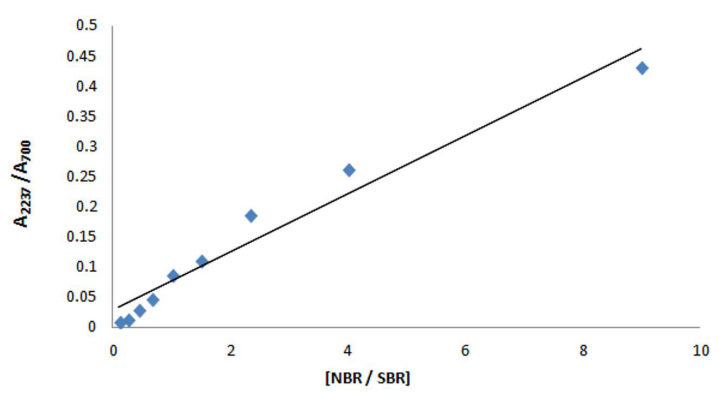

Figure 4. MIR/UATR calibration curve $\mathrm{A}_{223} / \mathrm{A}_{700}$ versus relative concentration $[\mathrm{NBR} / \mathrm{SBR}]$.

Figure 6 shows the calibration curve of NIR/ transmission (Bunsen burner pyrolysis) $\mathrm{A}_{4336} / \mathrm{A}_{4060}$ versus $[\mathrm{NBR}] /[\mathrm{SBR}]$ $(\% \mathrm{w} / \mathrm{w})$. From the calibration curve (Table 6$)$, the following correlation (Equation $7-\mathrm{R}=0.92$, with $85 \%$ of the values found, being explained by the developed methodology) is proposed:

$$
A_{4336} / A_{4060}=0.26[N B R] /[S B R]+2.58
$$

The methodology error was $1.33 \%$ (Table 6). Although the error is within the limits of the equipment accuracy, $\leq 2 \%$, there being no evidence of NBR low levels detection limit, the linearity is not as good as that found for the MIR, transmission and UATR methodologies.

\subsection{NIRA analysis of NBR/SBR}

To improve the results of NIR methodology, using the reflection method, the samples were analyzed by transflectance in this region (NIRA). The analytical bands chosen were the same. Figures 7-8, Table 7 and Equation 8 shows the results obtained. The methodology error was $0.74 \%$ (Table 7 ), with good linearity $\mathrm{R}=0.96$, and $92 \%$ of the data found were explained by this methodology. The error is within the limits of equipment accuracy, $\leq 2 \%$, and there is no evidence of limit of detection of low levels of NBR.

$$
A_{4336} / A_{4060}=0.30[N B R] /[S B R]+2.46
$$

To know the contents of unknown samples it is enough to analyze 5 aliquots of the rubber and to use the suitable calibration curves established in the developed methodologies, depending on the region of the infrared available in the laboratory. For example, Table 8 shows the evaluation of the MIR methodologies developed by means of analysis of unknown concentration NBR / SBR sample.

Although the test sample has been analyzed by the analyst, without the knowledge of its concentration, the 
Table 6. NIR transmission data (Bunsen burner pyrolysis) for calibration curve elaboration and associated methodology errors.

\begin{tabular}{cccc}
\hline $\begin{array}{c}\text { NBR/SBR } \\
\text { (Relative Concentration) }\end{array}$ & $\begin{array}{c}\mathbf{A}_{\mathbf{4 3 3 6}} / \mathbf{A}_{\mathbf{4 0 6 0}} \\
\text { (Median) }\end{array}$ & Mean standard deviation & RD (\%) \\
\hline $90 / 10(9.0)$ & 4.625 & 0.058 & 1.25 \\
$80 / 20(4.0)$ & 4.000 & 0.160 & 4.00 \\
$70 / 30(2.3)$ & 3.733 & 0.043 & 1,15 \\
$60 / 40(1.5)$ & 3.231 & 0.045 & 0.39 \\
$50 / 50(1.0)$ & 2.893 & 0.025 & 1.33 \\
$40 / 60(0.67)$ & 2.714 & 0.036 & 2.38 \\
$30 / 70(0.43)$ & 2.484 & 0.059 & 1.04 \\
$20 / 80(0.25)$ & 2.400 & 0.025 & 1.36 \\
$10 / 90(0.11)$ & 2.200 & 0.030 & \\
\hline
\end{tabular}

Table 7. NIRA data (pyrolysis in Bunsen burner) for calibration curve elaboration and associated methodology errors.

\begin{tabular}{cccc}
\hline $\begin{array}{c}\text { NBR/SBR } \\
\text { (Relative Concentration) }\end{array}$ & $\mathbf{A}_{4336} / \mathbf{A}_{\text {4060 }}$ (Median) & Mean standard deviation & RD (\%) \\
\hline $90 / 10(9.0)$ & 4.865 & 0.067 & 1.38 \\
$80 / 20(4.0)$ & 3.973 & 0.039 & 0.98 \\
$70 / 30(2.3)$ & 3.42 & 0.126 & 4.08 \\
$60 / 40(1.5)$ & 3.171 & 0.127 & 0.73 \\
$50 / 50(1.0)$ & 2.877 & 0.021 & 0.27 \\
$40 / 60(0.67)$ & 2.632 & 0.007 & 0.65 \\
$30 / 70(0.43)$ & 2.459 & 0.016 & 0.52 \\
$20 / 80(0.25)$ & 2.305 & 0.012 & 0.74 \\
\hline $0 / 90(0.11)$ & 2.161 & 0.016 & \\
\hline
\end{tabular}

Table 8. Data of unknown NBR/SBR sample $(\mathrm{X} / \mathrm{Y})$ for validation of MIR methodologies developed.

\begin{tabular}{|c|c|c|c|c|}
\hline $\begin{array}{c}\text { NBR/SBR(nominal relative concentration)/ } \\
\text { methodology }\end{array}$ & $\mathbf{A}_{2237} / \mathbf{A}_{700}$ & $\begin{array}{l}\mathbf{A}_{2237} / \mathbf{A}_{700} \\
\text { (median) }\end{array}$ & $\begin{array}{c}\text { Calculated } \\
\text { concentration }\end{array}$ & $\begin{array}{l}\text { RD } \\
(\%)\end{array}$ \\
\hline \multirow[t]{5}{*}{ Unknown sample $(\mathrm{X} / \mathrm{Y}) / \mathrm{MIR} /$ transmission } & 0.569 & 0.632 & $\mathrm{NBR}=74.29$ & 2.53 \\
\hline & 0.592 & & $\mathrm{SBR}=25.71$ & \\
\hline & 0.632 & & & \\
\hline & 0.644 & & & \\
\hline & 0.653 & & & \\
\hline \multirow[t]{5}{*}{ Unknown sample (X/Y)/ MIR/UATR } & 0.155 & 0.155 & $\mathrm{NBR}=71.43$ & 5.81 \\
\hline & 0.155 & & $\mathrm{SBR}=28.57$ & \\
\hline & 0.146 & & & \\
\hline & 0.192 & & & \\
\hline & 0.165 & & & \\
\hline
\end{tabular}

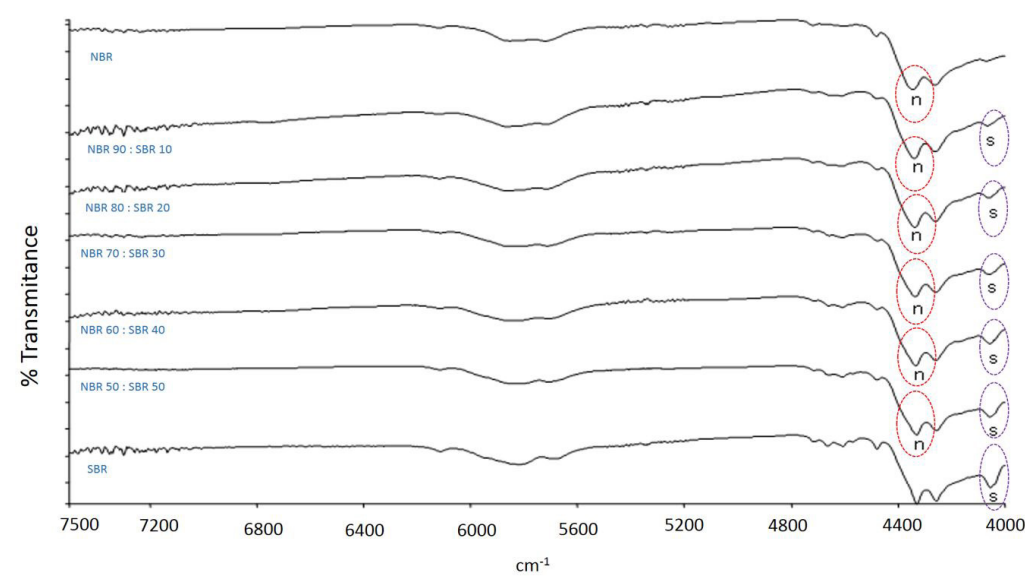

Figure 5. NIR transmission spectra (Bunsen burner pyrolysis) of NBR/SBR blends, with AN and styrene bands, labeled with $n$ and $s$, respectively. 


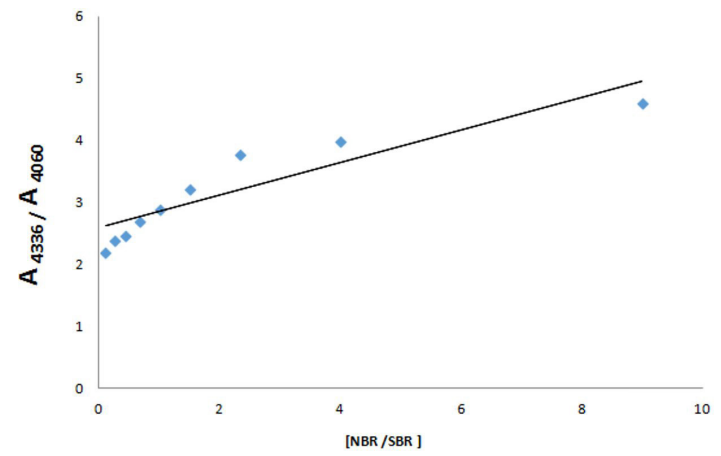

Figure 6. NIR calibration curve $\mathrm{A}_{4436} / \mathrm{A}_{4060}$ versus relative concentration [NBR/SBR].

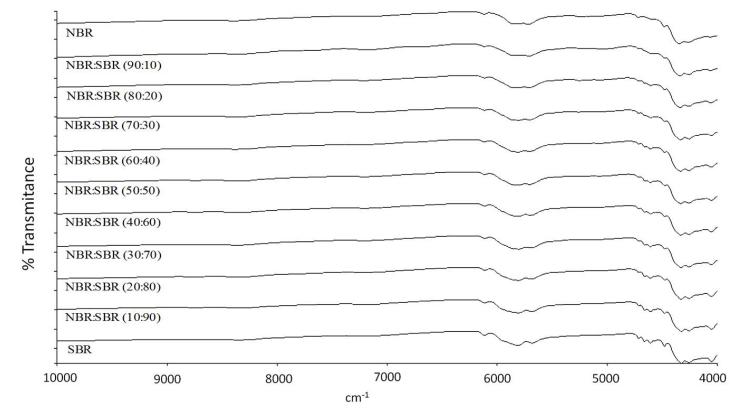

Figure 7. NIRA Spectra (pyrolysis in Bunsen burner) of NBR/ SBR blends.

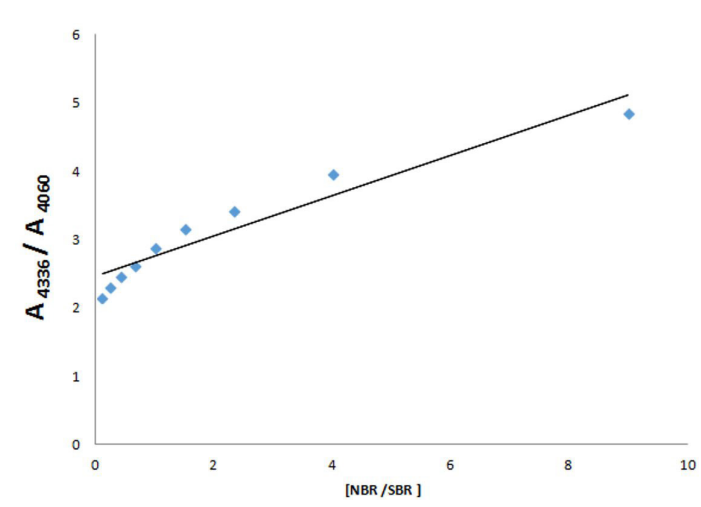

Figure 8. NIRA calibration curve $\mathrm{A}_{4436} / \mathrm{A}_{4060}$ versus relative concentration [NBR/SBR].

nominal value that should have been found would be around NBR70 / SBR30. Thus, both methodologies presented satisfactory values, with the best result for which UATR was used.

\section{Conclusion}

Summarily, all MIR and NIR methodologies were useful for NBR and SBR contents determination in the analyzed blends. The best correlation in the MIR region was found for the UATR methodology (pyrolysis in Bunsen burner), although there may be a detection limit between 10-20\% NBR and an error around $3 \%$. In the NIR region, the NIRA methodology showed better correlation, with no limit of detection and with error around $1 \%$, within the limits of the FT-IR spectrometer. Both methodologies MIR/NIR are fast, therefore useful as quality control in different industrial and research scenarios.

\section{Acknowledgements}

This study was supported in part by the National Senior Visiting Professor Program (PVNS) from the Coordenação de Aperfeiçoamento Pessoal de Nível Superior (CAPES).

\section{References}

1. Hemais, C. A., Rosa, E. O. R., \& Barros, H. M. (2000). Observações sobre desenvolvimentos Tecnológicos e os ciclos da Industria de Polímeros do Brasil. Polímeros: Ciência e Tecnologia, 10(3), 149-154. http://dx.doi.org/10.1590/S010414282000000300011.

2. Simielli, E. R. (1993). Principais características das blendas poliméricas fabricadas no Brasil. Polímeros: Ciência e Tecnologia, 3(1), 45-49. Retrieved in 2018, January 12, from http://www.revistapolimeros.org.br/pdf/v3n1/v3n1a06.pdf

3. Ramesan, M. T., Kuriakose, B., Pradeep, P., Alex, R., \& Varghese, S. (2001). Compatibilization of SBR/NBR blends using chemically modified styrene butadiene rubber. International Polymer Processing, 16(2), 183-191. http:// dx.doi.org/10.3139/217.1640.

4. Alcantara, A. F., Nunes, R. C. R., \& Visconte, L. L. Y. (2004). Mistura BR/SBR: propriedades mecânicas em função de modo de preparo. Polímeros: Ciência e Tecnologia, 14(4), 279-282. http://dx.doi.org/10.1590/S0104-14282004000400015.

5. Rocha, T. C. J., Soares, B. G., \& Coutinho, F. M. B. (2007). Principais copolímeros elastoméricos à base de butadieno utilizados na indústria automobilística. Polímeros: Ciência e Tecnologia, 17(4), 299-307. http://dx.doi.org/10.1590/S010414282007000400009.

6. Ramesan, M. T., \& Alex, R. (2001). Compatibilization of SBR/ NBR blends using chemically modified styrene-co-butadiene rubber - Part 2. Effect of compatibilizer loading. Polymer International, 50(12), 1298-1308. http://dx.doi.org/10.1002/ pi.775.

7. Pedreira, S. M., Pinto, J. R. A., Campos, E. A., Mattos, E. D. C., Oliveira, M. S., Jr., Oliveira, J. I. S., \& Dutra, R. D. C. L. (2016). Methodologies for characterization of aerospace polymers/energetic materials - a short review. Journal of Aerospace Technology and Management, 8(1), 18-25. http:// dx.doi.org/10.5028/jatm.v8i1.576.

8. Wikipedia. (2018). Nitrile rubber. Retrieved in 2018, January 12, from https://en.wikipedia.org/wiki/Nitrile_rubber

9. Sanches, N. B., Diniz, M. F., Alves, L. C., Dutra, J. C. N., Cassu, S. N., Azevedo, M. F. P., Mattos, E. C., \& Dutra, R. C. L. (2008). Avaliação da aplicabilidade de técnicas FT-IR de reflexão (UATR) e de transmissão para a determinação do teor de acrilonitrila (AN) em NBR. Polímeros: Ciência e Tecnologia, 18(3), 249-255. http://dx.doi.org/10.1590/S010414282008000300011.

10. Chakraborty, S., Bandyopadhyay, S., Ameta, R., Mukhopadhyay, R., \& Deuri, A. S. (2007). Application of FTIR in characterization of acrylonitrile-butadiene rubber (nitrile rubber). Polymer Testing, 26(1), 38-41. http://dx.doi. org/10.1016/j.polymertesting.2006.08.004.

11. Ghebremeskel, G. N., Sekinger, J. K., Hoffpauir, J. L., \& Hendrix, C. (1996). A study on the thermal degradation products of styrene-butadiene type rubber by pyrolysis/GC/ 
MS. Rubber Chemistry and Technology, 69(5), 874-884. http:// dx.doi.org/10.5254/1.3538409.

12. Yehia, A. A., Mansour, A. A., \& Stoll, B. (1997). Detection of compatibility of some rubber blends by DSC. Journal of Thermal Analysis, 48(6), 1299-1310. http://dx.doi.org/10.1007/ BF01983440.

13. Ferreira, A. C., Diniz, M. F., \& Mattos, E. C. (2018). FT-IR methodology transmission and UATR for quantifying automotive systems. Polimeros: Ciência e Tecnologia, 28(1), 6-14. http:// dx.doi.org/10.1590/0104-1428.2412.

14. Choi, S.-S., Kim, Y., \& Kwon, H.-M. (2014). Microstructural analysis and cis-transisomerization of BR and SBR vulcanizates reinforced with silica and carbon black using NMR and IR. RSCAdvances, 4(59), 31113-31119. http://dx.doi.org/10.1039/ C4RA03682D.

15. Perez, L. D., \& Lopez, B. L. (2012). Thermal characterization of SBR/NBR blends reinforced with a mesoporous silica. Journal of Applied Polymer Science, 125(S1), E327-E333. http://dx.doi.org/10.1002/app.35689.

16. Noriman, N. Z., Ismail, H., \& Rashid, A. A. (2010). Characterization of styrene butadiene rubber/recycled acrylonitrile-butadiene rubber (SBR/NBRr) blends: The effects of epoxidized natural rubber (ENR-50) as a compatibilizer. Polymer Testing, 29(2), 200-208. http://dx.doi.org/10.1016/j.polymertesting.2009.11.002.

17. Dutra, R. C. L., Diniz, M. F., Ribeiro, A. P., Lourenço, V. L., Cassu, S. N., \& Azevedo, M. P. (2004). Determinação do teor de NR/SBR em misturas: associação de dados DTG e FT-IR e/ ou ensaios auxiliares. Polímeros: Ciência e Tecnologia, 14(5), 334-338. http://dx.doi.org/10.1590/S0104-14282004000500011.

18. Shield, S. R., Ghebremeskel, G. N., \& Hendrix, C. (2001). Pyrolysis-GC/MS and TGA as tools for characterizing blends of SBR and NBR. Rubber Chemistry and Technology, 74(5), 803-813. http://dx.doi.org/10.5254/1.3547654.

19. Shield, S. R., \& Ghebremeskel, G. M. (2003). Use of mid and near infrared techniques as tools for characterizing blends of copolymers of styrene-butadiene and acrylonitrile-butadiene. Journal of Applied Polymer Science, 88(7), 1653-1658. http:// dx.doi.org/10.1002/app.11849.

20. Fernández-Berridi, M. J., González, N., Mugica, A., \& Bernicot, C. (2006). Pyrolysis-FTIR and TGA techniques as tools in the characterization of blends of natural rubber and SBR. Thermochimica Acta, 444(1), 65-70. http://dx.doi. org/10.1016/j.tca.2006.02.027.

21. Lee, S. Y., Lee, W., Cho, S., Kim, I., \& Ha, C. (2007). Quantitative analysis of unknown compositions in ternary polymer blends: a model study on NR/SBR/BR system. Journal of Analytical and Applied Pyrolysis, 78(1), 85-94. http://dx.doi.org/10.1016/j. jaap.2006.05.001.

22. Harada, M. (2015). Analytical methods for vulcanized rubbers. Nippon Gomu Kyokaishi, 88(6), 192-197. http://dx.doi. org/10.2324/gomu.88.192.

23. Ujianto, O., Putri, D. B., Jayatin, \& AWinarto, D. (2017). A comparative study of ground tire rubber devulcanization using twin screw extruder and internal mixer. IOP Conference Series. Materials Science and Engineering, 223, 012005. http://dx.doi. org/10.1088/1757-899X/223/1/012005.

24. Datta, S., Antos, J., \& Stocek, R. (2017). Characterisation of ground tyre rubber by using combination of FT-IR numerical parameter and DTG analysis to determine the composition of ternary rubber blend. Polymer Testing, 59, 308-315. http:// dx.doi.org/10.1016/j.polymertesting.2017.02.019.

25. Wake, W. C., Tidd, B. K., \& Loadman, M. J. R. (1983). Analysis of rubber and rubber-like polymer. 3rd ed. New York: Applied Science.

26. Rigoli, P. S., Murakami, L. M. S., Diniz, M. F., Azevedo, M. F. P., Cassu, S. N., Mattos, E. C., \& Dutra, R. C. L. (In press). Quantification of aerospace polymer blends by thermogravimetric analysis and infrared spectrometry. Journal of Aerospace Technology and Management.

27. Goddu, R. F. (1960). Near-infrared spectrophotometry. In C. N. Reilly (Ed.), Advances in analytical chemistry and instrumentation (pp. 347-425). New York: Interscience.

28. Mello, T. S. D., Diniz, M. F., \& Dutra, R. C. L. (2018). UATR and NIRA evaluation in the quantification of ATBC in NC blends. Polímeros: Ciência e Tecnologia, 28(3), 239-245. http://dx.doi.org/10.1590/0104-1428.16816.

29. Horák, V. M., \& Vítek, A. (1978). Interpretation and processing of vibrational spectra. New York: John Wiley \& Sons.

30. Damazio, D., Santos, R. P., Diniz, M. F., \& Dutra, R. C. L. (2015). Determinação do teor de ENB em EPDM (elastômero puro) por FT-IR de transmissão, por meio de banda relativa. Polímeros: Ciência e Tecnologia, 25(2), 181-185. http://dx.doi. org/10.1590/0104-1428.1777.

31. Grison, E. C., Becker, E., \& Sartori, E. (2010). Borrachas e seus aditivos, componentes, influencias e segredos. Porto Alegre: Letra e Vida.

32. Smith, A. L. (1979). Applied infrared spectroscopy. New York: John Wiley \& Sons.

Received: Feb. 01, 2018

Revised: May 22, 2018

Accepted: June 20, 2018 